\title{
Promoção de crescimento de arroz por rizóbios em diferentes níveis de adubação nitrogenada
}

\section{Growth promotion of rice by rhizobia at different levels of nitrogen fertilization}

\author{
Benjamin Dias Osorio Filho ${ }^{\mathrm{I}}$ Andréia Binz ${ }^{\mathrm{II}}$ Rafael Friedrich Lima ${ }^{\mathrm{II}}$ \\ Adriana Giongo ${ }^{\text {III }}$ Enilson Luiz Saccol de SáII
}

RESUMO

\begin{abstract}
Embora os rizóbios não apresentem a capacidade de fixar nitrogênio em plantas de arroz, estes podem estimular o crescimento da parte aérea e da raiz, aumentando a absorção de nutrientes, como o nitrogênio, e a produtividade. Com o trabalho, avaliou-se o efeito de rizóbios em promover o crescimento de plantas de arroz em função de doses de nitrogênio (N). Efetuouse um experimento com vasos contendo solo e plantas da cultivar IRGA 424. As plantas foram inoculadas com oito isolados de rizóbios e adubadas com doses equivalentes a 0,40, 80 e $160 \mathrm{~kg}$ $N \mathrm{ha}^{-1}$. Avaliou-se a matéria seca e a quantidade de $N$ acumulada na parte aérea e o perfilhamento das plantas. $O$ efeito do $N$ no crescimento de arroz aumentou com a inoculação de rizóbios. A matéria seca da parte aérea das plantas inoculadas e que receberam, aproximadamente, metade da maior dose de $N$ foi equivalente às que receberam a maior dose desse nutriente e sem inoculação. Além disso, a inoculação com rizóbios aumentou $o$ perfilhamento e a absorção de $N$. A inoculação de rizóbios em arroz, embora não dispense a adubação nitrogenada, tem potencial para aumentar a produção e a eficiência do uso do $\mathrm{N}$.
\end{abstract}

Palavras-chave: gramíneas, não-leguminosas, nitrogênio, Oryza sativa. ABSTRACT

Although rhizobia do not show the ability to fix nitrogen in rice plants, they can stimulate shoot and root growth and even increase productivity and also can increase the plant efficiency in the absorption of nutrients such as nitrogen. This study evaluated the effect of rhizobia in promoting the growth of rice plants fertilized with nitrogen $(N)$. An experiment was developed in pots containing soil and rice of the cultivar IRGA 424. The plants were inoculated with eight isolates of rhizobia and fertilized with $0,40,80$ and $160 \mathrm{~kg} \mathrm{~N} \mathrm{ha}^{-1}$. We evaluated the dry matter of shoots, tillering and amounts of $N$ absorbed by the shoots. The effect of
$N$ on rice growth increased by inoculation of rhizobia. Inoculated plants and fertilized with approximately half of the higher $N$ dose, produced shoot equivalent of the plants that received the highest dose of this nutrient and without inoculation. Moreover, inoculation with rhizobia increased tillering and absorption of $N$. The practice of rhizobia inoculation in rice, although not replace the nitrogen fertilization, have great potential for rice farmers, allowing greater production and efficiency of $N$ use.

Key words: Poaceae, non-legumes, nitrogen, Oryza sativa.

\section{INTRODUÇÃO}

O nitrogênio (N) é essencial para as células vivas, fazendo parte de muitas moléculas orgânicas, como aminoácidos e proteínas. Em geral, a concentração desse nutriente no tecido vegetal varia de 2 a 4\% (MENGEL \& KIRKBY, 1897) e a demanda de $\mathrm{N}$ das culturas agrícolas é expressiva. A aplicação de $\mathrm{N}$ no solo é inerente à produtividade elevada das culturas agrícolas. No entanto, o $\mathrm{N}$ aplicado está sujeito a transformações e movimentações no solo, resultando em perdas e contaminações, que variam com a atividade microbiana, o clima, as propriedades químicas e físicas do solo e com o estádio fenológico da planta.

Em se tratando de $\mathrm{N}$, os rizóbios são extremamente importantes na agricultura, porque fixam $\mathrm{N}$ da atmosfera, em simbiose com leguminosas, transferindo-o às plantas e ao solo. Em plantas não

\footnotetext{
'Universidade Estadual do Rio Grande do Sul (UERGS), Rua Sete de Setembro, 1040, 96508-010, Cachoeira do Sul, RS, Brasil. E-mail: benjamin-filho@uergs.edu.br. Autor para correspondência.

IIDepartamento de Solos, Faculdade de Agronomia, Universidade Federal do Rio Grande do Sul (UFRGS), Porto Alegre, RS, Brasil.

III Laboratório de Geobiologia, Instituto do Petróleo e dos Recursos Naturais (IPR), Pontifícia Universidade Católica do Rio Grande do Sul (PUCRS), Porto Alegre, RS, Brasil.
} 
leguminosas, os rizóbios não formam nódulos e não fixam o $\mathrm{N}$ atmosférico. Por outro lado, estudos recentes demonstraram que os rizóbios podem colonizar caules e folhas de plantas como o arroz, o milho, o trigo e a canola, entre muitas outras (PERRINE-WALKER et al., 2007; YANNI \& DAZZO, 2010; OSORIO FILHO et al., 2014; HAHN et al., 2014). Vivendo endofiticamente, os rizóbios podem estimular o crescimento das plantas, devido à produção de substâncias hormonais, principalmente auxinas (BISWAS et al., 2000), a solubilização de fosfatos (RODRIGUEZ \& FRAGA, 1999) e a proteção das plantas contra patógenos (MISHRA et al., 2006).

A entrada dos rizóbios em plantas de arroz ocorre em aberturas radiciais resultantes da emergência de raízes secundárias. Do sistema radicular, essas bactérias ascendem pelo xilema para a parte aérea (YANNI \& DAZZO, 2010). Em arroz, os rizóbios podem acelerar a germinação das sementes, estimular o crescimento radicial, melhorar a absorção de nutrientes, estimular o crescimento da parte aérea e aumentar o rendimento de grãos (BISWAS et al., 2000; YANNI et al., 2001). A promoção no crescimento e no desenvolvimento de arroz é atribuída à produção de ácido-indol-acético (AIA) pelos rizóbios, cujo precursor inicial é o aminoácido triptofano (SPAEPEN et al., 2007).

Apesar de não fixar $\mathrm{N}$ quando associados com arroz, os rizóbios podem estimular o crescimento radicular e aumentar o aproveitamento dos nutrientes do solo, incluindo o N. Com o trabalho, avaliouse a promoção de crescimento que os rizóbios proporcionam em plantas de arroz fertilizadas com diferentes doses de $\mathrm{N}$.

\section{MATERIAL E MÉTODOS}

Foi desenvolvido um experimento com vasos plásticos de 2,5L, contendo $1,7 \mathrm{~kg}$ de solo, em casa de vegetação, no Departamento de Solos da Universidade Federal do Rio Grande do Sul. O delineamento experimental foi inteiramente casualizado, com três repetições em esquema bifatorial (combinações entre isolados de rizóbios e doses de $\mathrm{N}$ em cobertura). $\mathrm{O}$ solo (Chernossolo Ebânico) foi coletado em campo com pastagens naturais, em Caçapava do Sul, Rio Grande do Sul/ RS (Coordenadas 3042'32.39'S; 5342'35.18'O). A camada amostrada foi de 0 a $20 \mathrm{~cm}$. Após a coleta, o solo foi peneirado em malha de $20 \mathrm{~mm}$. O solo foi analisado com os métodos de análises de rotina adotados no RS e em Santa Catarina (CQFS-RS/SC, 2004). Os resultados indicaram: argila $=20 \%, \mathrm{pH}_{\mathrm{H} 20}=5,2$, Índice $\mathrm{SMP}=6,0$; $\mathrm{P}=8 \mathrm{mg} \mathrm{dm}^{-3}, \mathrm{~K}=95 \mathrm{mg} \mathrm{dm}^{-3}$, matéria orgânica $=3,8 \%$, $\mathrm{Al}=0,6 \mathrm{cmol}_{\mathrm{c}} \mathrm{dm}^{-3}, \mathrm{Ca}=7,9 \mathrm{cmol}_{\mathrm{c}} \mathrm{dm}^{-3}, \mathrm{Mg}=3,0 \mathrm{cmol}_{\mathrm{c}}$ $\mathrm{dm}^{-3}, \mathrm{~S}=6,1 \mathrm{mg} \mathrm{dm}^{-3}, \mathrm{Zn}=1,9 \mathrm{mg} \mathrm{dm}^{-3}, \mathrm{Cu}=1,7 \mathrm{mg} \mathrm{dm}^{-{ }^{c}}$, $\mathrm{B}=0,4 \mathrm{mg} \mathrm{dm}^{-3} \mathrm{e} \mathrm{Mn}=45 \mathrm{mg} \mathrm{dm}^{-3}$. O solo foi fertilizado com superfosfato triplo $\left(219 \mathrm{mg} \mathrm{kg}^{-1}\right)$ e cloreto de potássio $\left(86 \mathrm{mg} \mathrm{kg}^{-1}\right)$, equivalendo a $90 \mathrm{~kg} \mathrm{P}_{2} \mathrm{O}_{5}$ ha $^{-1}$ e a $50 \mathrm{~kg} \mathrm{~K}_{2} \mathrm{O}$ ha $^{-1}$, de acordo com as sugestões de adubação (CQFS$\mathrm{RS} / \mathrm{SC}, 2004)$, antes de ser acondicionado nos vasos. Para o cálculo da quantidade aplicada de $\mathrm{P}_{2} \mathrm{O}_{5}$ e de $\mathrm{K}_{2} \mathrm{O}$, considerou-se a camada de 0 a $20 \mathrm{~cm}$. Os vasos foram perfurados na lateral inferior, e por meio de uma rolha de silicone de $20 \mathrm{~mm}$ de diâmetro, foi efetuado o controle da drenagem.

Foi utilizada a cultivar de arroz IRGA 424. Os isolados de rizóbios utilizados constam na tabela 1 e foram selecionados por apresentarem significativa produção de AIA, em análises espectrofotométricas anteriores. Os isolados UFRGS-Lc336, UFRGSLg111 e UFRGS-1TV foram identificados geneticamente por OSORIO FILHO et al. (2014) e o isolado UFRGS-VP16 foi identificado por HAHN et al. (2014). As espécies dos demais isolados ainda são desconhecidas. As sementes foram inoculadas com o caldo levedura manitol (LM), contendo o isolado crescido, por 24 horas e, após, semeadas no solo.

Foram utilizados tratamentos controle sem inoculação. Cada vaso recebeu 16 sementes. Dez dias

Tabela 1 - Isolados, espécies, locais de coleta, planta hospedeira e referências dos rizóbios utilizados.

\begin{tabular}{lllll}
\hline Isolado & \multicolumn{1}{c}{ Espécie } & Local de coleta & \multicolumn{2}{c}{ Planta hospedeira } \\
\hline UFRGS-Lc336 & Bradyrhizobium japonicum & Hulha Negra, RS & Lotus corniculatus & FRIZZO, 2007 \\
UFRGS-Lc348 & ainda indeterminada & Hulha Negra, RS & L. corniculatus & FRIZZO, 2007 \\
UFRGS-Lc398 & ainda indeterminada & Hulha Negra, RS & L. corniculatus & FRIZZO, 2007 \\
UFRGS-Lg111 & Mesorhizobium amorphae & Porto Alegre, RS & L. glaber & FONTOURA, 2007 \\
UFRGS-Ls36 & ainda indeterminada & Mostardas, RS & L. subbiflorus & FONTOURA, 2007 \\
EEL1183 & ainda indeterminada & Lages, SC & L. uliginosus & BROSE, 1992 \\
UFRGS-1TV & Rhizobium leguminosaum bv. Viciae & Dom Pedrito, RS & Trifolium vesiculosum & BREDOW, 2005 \\
UFRGS-VP16 & Burkholderia sp. & Veranópolis, RS & T. repens & BREDOW, 2005 \\
\hline
\end{tabular}

Ciência Rural, v.46, n.3, mar, 2016. 
após a semeadura, efetuou-se o desbaste, mantendo-se duas plantas por vaso. As quantidades de $\mathrm{N}$ aplicadas equivaleram a $0,40,80$ e $160 \mathrm{~kg} \mathrm{ha}^{-1}$, parceladas em duas aplicações. $\mathrm{O} \mathrm{N}$ foi aplicado em solução composta com ureia, nas respectivas concentrações de $0 ; 0,378 ; 0,755$ e $1,510 \mathrm{mg} \mathrm{L}^{-1}$. Para determinação dessas concentrações, considerou-se que o $\mathrm{N}$ aplicado abrangeu a camada de 0 a $20 \mathrm{~cm}$. A primeira e a segunda aplicação de $\mathrm{N}$ ocorreram aos 10 e 30 dias após a semeadura, respectivamente. Imediatamente após a primeira fertilização nitrogenada de cobertura, o solo foi mantido alagado.

Aos 55 dias após a semeadura, a parte aérea foi cortada, seca em estufa a $65^{\circ} \mathrm{C}$ por 48 horas, pesada e moída. Determinou-se o teor de $\mathrm{N}$ total do tecido (TEDESCO et al., 1995). Para o cálculo das quantidades de $\mathrm{N}$ absorvidas pelas plantas, multiplicaram-se os valores de matéria seca pelo teor deste elemento no tecido vegetal. Os resultados obtidos foram submetidos à análise da variância (Tabela 2). Quando houve interação entre os tratamentos, foram realizadas análises de regressão para o fator dose, para cada rizóbio avaliado. Quando não houve interação, as médias de cada rizóbio, nas quatro doses testadas, foram submetidas ao teste de Tukey $(\mathrm{P}<0,05)$. As análises de regressões foram realizadas pelo programa estatístico Bioestat (AYRES et al., 2007).

\section{RESULTADOS E DISCUSSÃO}

A inoculação com rizóbios incrementou a produção de matéria seca da parte área das plantas de arroz (Figura 1). Devido à interação entre os fatores doses de $\mathrm{N}$ e rizóbios (Tabela 2), cada bactéria inoculada teve um efeito diferenciado no crescimento da parte aérea em função das doses de $\mathrm{N}$. O incremento da parte aérea em função da adubação nitrogenada foi mais pronunciado quando houve inoculação de rizóbios, independentemente do isolado testado. O isolado UFRGS-Lc348 destacouse por estimular a produção da parte aérea de arroz em 19\%, sem aplicação de N (Figura 1B). Com a aplicação de $160 \mathrm{~kg} \mathrm{ha}^{-1}$ de $\mathrm{N}$, o rizóbio UFRGSLg111, da espécie Mesorhizobium amorphae, incrementou em $55 \%$ a produção de matéria seca da parte aérea (Figura 1D). Em outro trabalho, este mesmo isolado, assim com o isolado UFRGS-1TV, pertencente à espécie Rhizobium leguminosaum bv. Viciae foram visualizados colonizando raízes e parte aérea de plantas de arroz, cultivar IRGA 424, por meio de marcação com o gene gus A (OSORIO FILHO et al., 2014). Na média entre todos os isolados testados, a matéria seca da parte aérea foi incrementada pelos rizóbios em 11, 21, 29 e 39\%, nas doses de 0, 40, 80 e $160 \mathrm{~kg} \mathrm{ha}^{-1}$ de $\mathrm{N}$, respectivamente. Esses valores foram superiores aos observados por MISHRA et al. (2006), que estudaram o efeito de dois isolados de rizóbios em arroz e obtiveram incremento de 5,14\% na matéria seca da parte aérea das plantas. Estes autores também observaram que os isolados produziram ácidos fenólicos, promovendo a resistência das plantas de arroz ao ataque de Rhizoctonia solani. Em outros trabalhos, foram observados incrementos de 19\% (BISWAS et al., 2000) e de 32\% (CHI et al., 2005) na produção de matéria seca de arroz inoculado com diferentes estirpes de rizóbios.

Tabela 2 - Análise da variância das variáveis avaliadas.

\begin{tabular}{|c|c|c|c|c|c|}
\hline Fonte de variação & Grau de liberdade & Soma dos quadrados & Quadrado médio & Valor F & Valor $\mathrm{p}$ \\
\hline \multicolumn{6}{|c|}{ 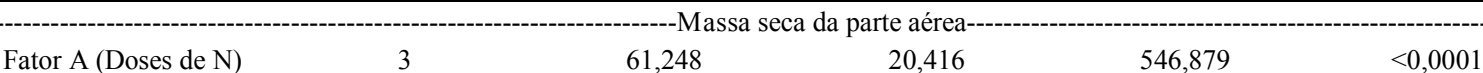 } \\
\hline Fator B (Rizóbios) & 8 & 5,739 & 0,717 & 19,217 & $<0,0001$ \\
\hline Interação A x B & 24 & 5,307 & 0,221 & 5,923 & $<0,0001$ \\
\hline Erro & 72 & 2,688 & 0,037 & & \\
\hline Fator A (Doses de N) & 3 & 614,008 & 204,669 & 174,793 & $<0,0001$ \\
\hline Fator B (Rizóbios) & 8 & 28,427 & 3,553 & 3,035 & 0,006 \\
\hline Interação A x B & 24 & 43,765 & 1,824 & 1,557 & 0,0773 \\
\hline Erro & 72 & 84,307 & 1,171 & & \\
\hline \multicolumn{6}{|c|}{-Acúmulo de N na parte área----------- } \\
\hline Fator A (Doses de N) & 3 & $9.455,351$ & $3.151,784$ & 329,905 & $<0,0001$ \\
\hline Fator B (Rizóbios) & 8 & 449,858 & 56,232 & 5,886 & $<0,0001$ \\
\hline Interação A x B & 24 & 746,684 & 31,112 & 3,257 & 0,0001 \\
\hline Erro & 72 & 687,861 & 9,554 & & \\
\hline
\end{tabular}



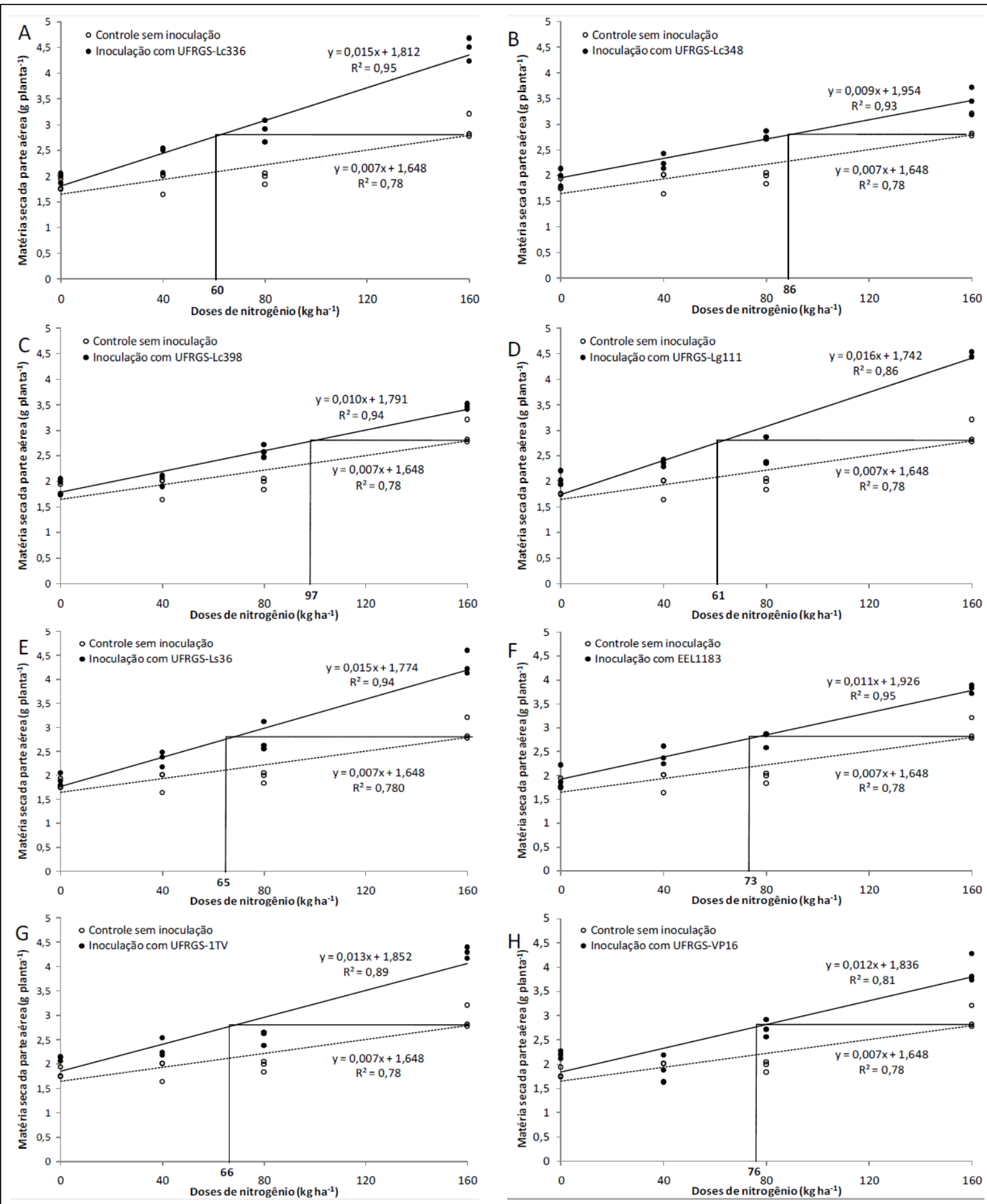

Figura 1 - Matéria seca da parte aérea de plantas de arroz (cultivar IRGA 424), sem inoculação e inoculadas com os rizóbios UFRGS-Lc336 (A), UFRGS-Lc348 (B), UFRGS-Lc398 (C), UFRGS-Lg111 (D), UFRGS-Ls36 (E), EEL1183 (F), UFRGS-1TV (G) e UFRGSVP16 $(\mathrm{H})$ em doses crescentes de N.

Os resultados obtidos mostraram que o uso de rizóbios possibilitou a produção da mesma quantidade de matéria seca da parte aérea, em doses menores de $\mathrm{N}$, em relação aos tratamentos sem inoculação. O isolado UFRGS-Lc336, associado a uma dose de $60 \mathrm{~kg} \mathrm{ha}^{-1}$ de $\mathrm{N}$, proporcionou uma produção 
de matéria de parte aérea equivalente ao obtido com a dose de $160 \mathrm{~kg} \mathrm{ha}^{-1}$ de $\mathrm{N}$, sem inoculação de rizóbios (Figura 1A). Supondo que a produtividade de arroz esteja diretamente relacionada com a produção de matéria seca, pode-se dizer que a inoculação com o isolado UFRGS-Lc336 proporcionaria economia na adubação nitrogenada. Esse resultado demonstrou o potencial que esta bactéria, da espécie Bradyrhizobium japonicum, possui na promoção de crescimento de arroz, indicando a necessidade de experimentos de campo com diferentes doses de $\mathrm{N}$. Em um estudo com quatro variedades de arroz, esta mesma bactéria foi capaz de acelerar a germinação de sementes, estimular o crescimento da parte aérea e do sistema radicular e aumentar o perfilhamento de plantas de arroz da cultivar IRGA 424 (OSORIO FILHO et al., 2014).

A inoculação com alguns dos rizóbios testados estimulou o perfilhamento de arroz (Tabela 3 ), entretanto, esta variável não foi influenciada pela interação entre os fatores doses de $\mathrm{N}$ e inoculação com rizóbios (Tabela 2). Os isolados UFRGSLc336, UFRGS-Ls36, EEL1183 e UFRGS-1TV aumentaram o número de perfilhos por planta, em aproximadamente $40 \%$. Com a dose de $160 \mathrm{~kg} \mathrm{ha}^{-1}$ de $\mathrm{N}$, os isolados UFRGS-Lg111 e UFRGS-Lc336 estimularam o perfilhamento em mais de $70 \%$. Na média de todos os rizóbios estudados, a emissão de perfilhos foi incrementada pela inoculação em 21 , 16,19 e $58 \%$, nas doses de $0,40,80$ e $160 \mathrm{~kg} \mathrm{ha}^{-1}$ de N, respectivamente. Quando se aplicou $160 \mathrm{~kg}$ ha $^{-1}$, o número de perfilhos foi de seis por planta nos tratamentos sem inoculação, mas, quando as plantas foram inoculadas com rizóbios, a média do número de perfilhos por planta foi de 11 . O aumento do número de perfilhos por planta é de extrema importância para a produção de arroz, pois cada estrutura dessas poderá formar uma panícula. Assim, plantas com maior produção de panículas têm maior rendimento de grão. Em um estudo feito na Índia, o número de panículas de arroz aumentou em média $23,3 \%$, quando as plantas foram inoculadas com estirpes de rizóbios (MISHRA et al., 2006).

Além da possível economia que as estirpes de rizóbios podem proporcionar na cultura de arroz, os resultados também mostram que a inoculação com estes microrganismos melhorou o aproveitamento do $\mathrm{N}$ do solo ou do fertilizante. A quantidade absorvida e acumulada desse nutriente na parte aérea das plantas de arroz aumentou com as doses de N (Figura 2), variando com a interação entre os fatores testados (Tabela 2). Esse incremento foi maior quando as plantas foram inoculadas com os isolados de rizóbios. Alguns isolados apresentaram maior efeito no aumento da absorção em situações de menor disponibilidade de N. Nessa perspectiva, o rizóbio EEL1183 aumentou em 56\% a absorção de $\mathrm{N}$, mesmo quando este nutriente não foi aplicado (Figura 2F). Por outro lado, o estímulo dos isolados UFRGS-Lc336 e UFRGS 1-TV na absorção de N foi mais pronunciado em doses elevadas de N. Com a dose de $160 \mathrm{~kg} \mathrm{ha}^{-1}$ de $\mathrm{N}$, o acúmulo de $\mathrm{N}$ na parte aérea das plantas inoculadas com estes dois isolados foi $29 \%$ superior ao das plantas do tratamento controle e sem inoculação. Este incremento é muito próximo

Tabela 3 - Número de perfilhos por planta de arroz, cultivar 'IRGA 424', em função da inoculação com isolados de rizóbios e aplicação de doses crescentes de $\mathrm{N}$.

\begin{tabular}{|c|c|c|c|c|c|}
\hline \multirow{2}{*}{ Isolados de rizóbios } & \multicolumn{4}{|c|}{ 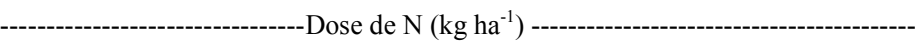 } & \multirow{2}{*}{ Média } \\
\hline & 0 & 40 & 80 & 160 & \\
\hline UFRGS-Lc336 & 3,5 & 4,0 & 5,5 & 10,7 & $5,9 \mathrm{a}^{*}$ \\
\hline UFRGS-Lc348 & 3,3 & 3,3 & 5,3 & 9,2 & $5,3 \mathrm{ab}$ \\
\hline UFRGS-Lc398 & 3,3 & 3,7 & 4,8 & 9,7 & $5,4 \mathrm{ab}$ \\
\hline UFRGS-Lg111 & 3,5 & 3,2 & 3,8 & 11,0 & $5,4 \mathrm{ab}$ \\
\hline UFRGS-Ls36 & 3,8 & 3,5 & 5,2 & 10,2 & $5,7 \mathrm{a}$ \\
\hline EEL1183 & 4,3 & 5,2 & 5,0 & 9,3 & $5,9 \mathrm{a}$ \\
\hline UFRGS-1TV & 4,5 & 4,0 & 5,2 & 10,2 & $5,9 \mathrm{a}$ \\
\hline UFRGS-VP16 & 4,8 & 2,8 & 5,3 & 9,2 & $5,5 \mathrm{ab}$ \\
\hline Controle sem inoculação & 3,2 & 3,2 & 4,2 & 6,3 & $4,2 \mathrm{~b}$ \\
\hline Média & $3,8^{* *}$ & 3,6 & 4,9 & 9,5 & \\
\hline
\end{tabular}

*Médias seguidas pela mesma letra não diferem pelo teste de Tukey a 5\% de probabilidade de erro.

${ }^{* *}$ Incremento quadrático (número de perfilhos $=0,0003$ dose $^{2}-0,01$ dose $+3,7522\left(\mathrm{R}^{2}=0,80\right)$ ). 

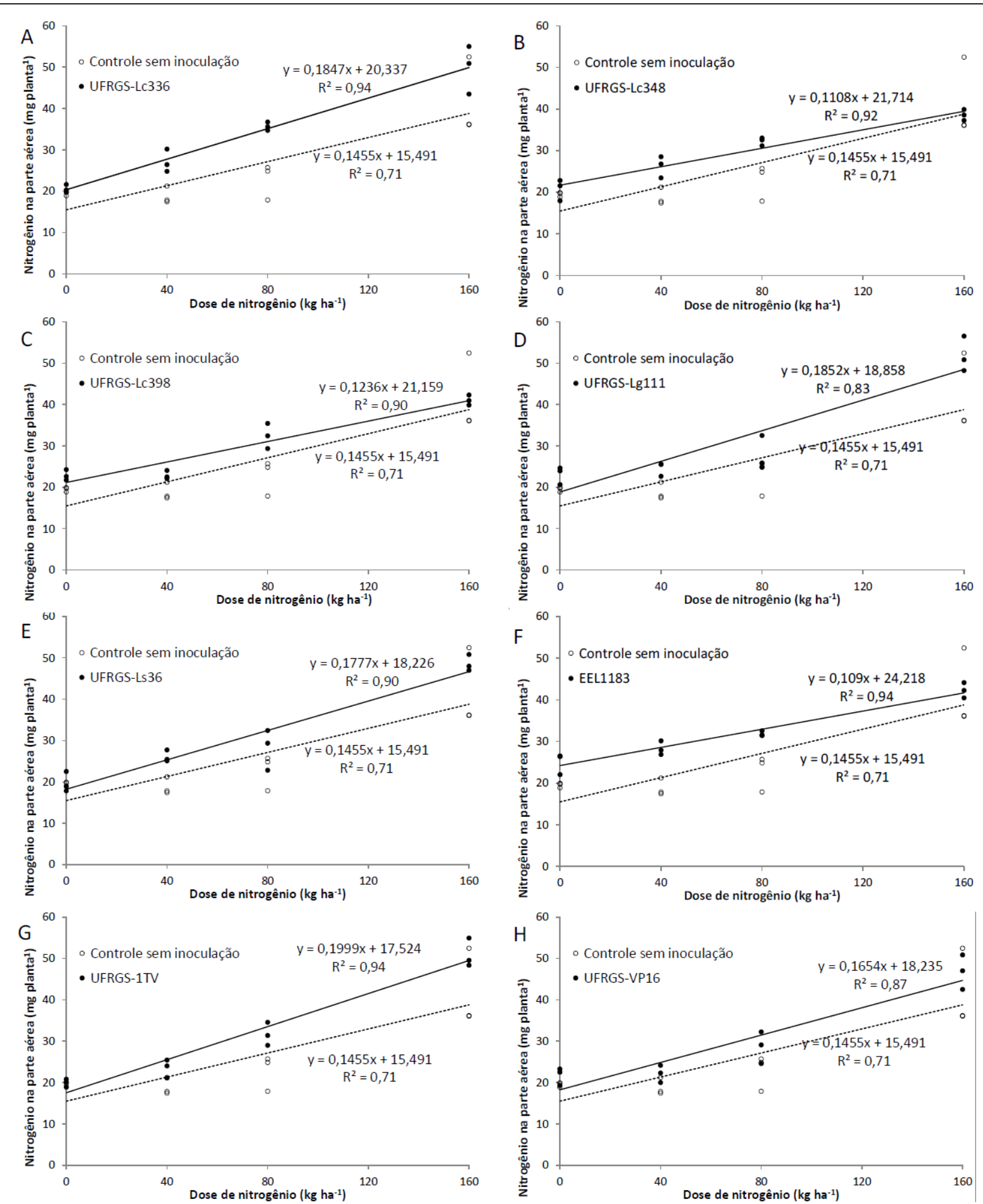

Figura 2 - Nitrogênio absorvido pela parte aérea de plantas de arroz (cultivar IRGA 424), sem inoculação e inoculadas com os rizóbios UFRGS-Lc336 (A), UFRGS-Lc348 (B), UFRGS-Lc398 (C), UFRGS-Lg111 (D), UFRGS-Ls36 (E), EEL1183 (F), UFRGS$1 T V(G)$ e UFRGS-VP16 (H) em doses crescentes de N.

ao observado por BISWAS et al. (2000), de 32,2\%, quando estes autores inocularam cinco estirpes de rizóbios no arroz.
A promoção do crescimento de arroz pelos isolados de rizóbios foi mais pronunciada conforme se aumentou a dose de N. Em não leguminosas, os 
rizóbios não são capazes de fixar $\mathrm{N}$, por não haver possibilidades genéticas de formação de nódulos. Por conseguinte, essas bactérias não conseguem desempenhar a atividade diazotrófica. Dessa forma, a inoculação de rizóbios em arroz não tem a pretensão de substituir a adubação nitrogenada. Por outro lado, os resultados indicaram que o aumento da dose de $\mathrm{N}$ estimula a promoção de crescimento e isso, provavelmente, ocorreu pela maior síntese de triptofano. Esse aminoácido é precursor da síntese de AIA, principal auxina natural responsável pelo estimulo ao crescimento vegetal (SPAEPEN et al., 2007). Os rizóbios são capazes de utilizar o triptofano, sintetizado com $\mathrm{N}$ oriundo do solo e, por meio de distintas rotas metabólicas, dependendo da espécie, produzir AIA. De acordo com OSORIO FILHO et al. (2014), os isolados UFRGS-Lc336, UFRGS-Lg111 e UFRGS-1TV foram capazes de sintetizar AIA pela rota do indol acetonitrilo (IAN).

Os resultados obtidos neste estudo reforçaram o potencial de isolados de rizóbios em promover o crescimento de plantas de arroz, concordando com pesquisas realizadas em outros países (BISWAS et al., 2000; YANNI et al., 2001; CHI et al., 2005; MISHRA et al., 2006). Embora o efeito da promoção de crescimento tenha aumentado com o acréscimo da dose de $\mathrm{N}$, os resultados também indicaram que a inoculação de rizóbios proporcionou melhor aproveitamento do $\mathrm{N}$ aplicado, pois aumentou o acúmulo deste elemento e proporcionou maior eficiência na adubação. Com o elevado preço dos fertilizantes nitrogenados, a economia com esses insumos significaria redução nos custos da lavoura e aumento na renda agrícola. Além disso, com a maior absorção de $\mathrm{N}$ pelas plantas inoculadas, pode-se diminuir as perdas com a adubação nitrogenada e a consequente poluição ambiental.

\section{CONCLUSÃO}

Os rizóbios estudados aumentam a produção de matéria seca da parte aérea da cultivar IRGA 424. A magnitude desse efeito aumenta com a dose de nitrogênio aplicada. Os rizóbios testados estimulam o crescimento das plantas de arroz, possibilitando diminuir as doses de nitrogênio aplicadas nessa cultura.

\section{REFERÊNCIAS}

AYRES, M. et al. BioEstat 5.0 Aplicações estatísticas nas áreas das ciências biológicas e médicas. Belém: Sociedade Civil Mamirauá CNPq, 2007. 324p.
BISWAS, J.C. et al. Rhizobial inoculation influences seedling vigor and yield of rice. Agronomy Journal, v.92, n.5, p.880886, 2000. Disponível em: <https://dl.sciencesocieties.org/ publications/aj/abstracts/92/5/880>. Acesso em: 17 jan. 2015. doi: 10.2134/agronj2000.925880x.

BREDOW, J. Seleção de rizóbios para trevo branco. 2005. 66f. (Mestrado em Ciência do Solo) - Programa de Pós-graduação em ciência do solo. Universidade Federal do Rio Grande do Sul, RS.

BROSE, E. Seleção de rizóbio para Lotus pedunculatus em solo ácido. Pesquisa Agropecuária Brasileira, v.27, n.3, p.409-415, 1992. Disponível em: <http://seer.sct.embrapa.br/index.php/pab/ article/view/3663/954>. Acesso em: 17 jan. 2015.

CHI, F. et al. Ascending migration of endophytic rhizobia, from roots to leaves, inside rice plants and assessment of benefits to rice growth physiology. Applied and Environmental Microbiology, v.71, n.11, p.7271-7278, 2005. Disponível em: <http://www.ncbi. nlm.nih.gov/pmc/articles/PMC1287620/>. Acesso em: 17 jan. 2015. doi: 10.1128/AEM.71.11.7271-7278.2005.

CQFS (COMISSÃO DE QUÍMICA E FERTILIDADE DO SOLO) RS/SC. Manual de adubação e calagem para os estados do Rio Grande do Sul e Santa Catarina. 10.ed. Porto Alegre: Sociedade Brasileira de Ciência do Solo - Núcleo Regional Sul, 2004. 400p.

FONTOURA, R.A. Isolamento de rizóbios nativos para Lotus subbiflorus e L.glaber em solos do Rio Grande do Sul. 2007. 82f. (Mestrado em Microbiologia Agrícola e do Ambiente) Programa de Pós-graduação em Microbiologia Agrícola e do Ambiente, Universidade Federal do Rio Grande do Sul, RS.

FRIZZO, M.L.S. Isolamento de rizóbios nativos para Lotus corniculatus e L. uliginosus em solos do Rio Grande do Sul. 2007. 68f. (Mestrado em Ciência do Solo) - Programa de Pósgraduação em Ciência do Solo, Universidade Federal do Rio Grande do Sul, RS.

HAHN, L. et al. Growth promotion in maize with diazotrophic bacteria in succession with ryegrass and white clover. American and Eurasian Journal of Agriculture \& Environmental Science, v.14. n.1, p.11-16, 2014. Disponível em: <http://www.idosi.org/ aejaes/jaes14\%281\%2914/3.pdf>. Acesso em: 17 jan. 2015. doi: 10.5829/idosi.aejaes.2014.14.01.11893.

MENGEL, K.; KIRKBY, E.A. Principles of plant nutrition Berna: International Potash Institute, 1987. 687p.

MISHRA, R.P.N. et al. Rhizobium-mediated induction of phenolics and plant growth promotion in rice (Oryza sativa L.). Current Microbiology, v.52, n.5, p.383-389, 2006. Disponível em: <http://www.ncbi.nlm.nih.gov/pubmed/16586021>. Acesso em: 17 jan. 2015. doi: 10.1007/s00284-005-0296-3.

OSORIO FILHO, B.D. et al. Rhizobia enhance growth in rice plants under flooding conditions. American and Eurasian Journal of Agriculture \& Environmental Science, v.14. n.8, p.707-718, 2014. Disponível em: <http://www.idosi.org/aejaes/ jaes14(8)14/4.pdf>. Acesso em: 17 jan. 2015. doi: 10.5829/idosi. aejaes.2014.14.08.12377.

PERRINE-WALKER, F.M. et al. Infection process and the interaction of rice roots with rhizobia. Journal of Experimental Botany, v.58, n.12, p.3343-3350, 2007. Disponível em: $<$ http://jxb.oxfordjournals. org/content/58/12/3343.full>. Acesso em: 17 jan. 2015.

Ciência Rural, v.46, n.3, mar, 2016. 
RODRIGUEZ, H.; FRAGA, R. Phosphate solubilizing bactéria and their role in plant growth promotion. Biotechnology Advances, v.17, n.4-5, p.319-339, 1999. Disponível em: <http:// www.sciencedirect.com/science/article/pii/S0734975099000142>. Acesso em: 17 jan. 2015. doi: 10.1016/S0734-9750(99)00014-2.

SPAEPEN, S. etal. Indole-3-acetic acid in microbial and microorganismplant signaling. Federation of European Microbiological, v.31, p.425-448, 2007. Disponível em: <http://www.ncbi.nlm.nih.gov/ pubmed/17509086>. Acesso em: 17 jan. 2015.

TEDESCO, M.J. et al. Análise de solo, plantas e outros materiais. 2.ed. Porto Alegre: UFRGS, 1995. 215p. (Boletim Técnico, 5).
YANNI, Y.G. et al. The beneficial plant growth-promoting association of Rhizobium leguminosarum bv. Trifolli with rice roots. Australian Journal Plant of Physiology, v.28, n.9, p.845870, 2001. Disponível em: <http:/www.publish.csiro.au/paper/ PP01069.htm>. Acesso em: 17 jan. 2015. doi: 10.1071/PP01069.

YANNI, Y.G.; DAZZO, F.B. Enhancement of rice production using endophytic strains of Rhizobium leguminosarum bv. trifolii in extensive field inoculation trials within the Egypt Nile Delta. Plant and Soil, v.336. p.129-142, 2010. Disponível em: <http:// link.springer.com/article/10.1007\%2Fs11104-010-0454-7\#page-1>. Acesso em: 17 jan. 2015. doi: 10.1007/s11104-010-0454-7. 